\title{
Correction to: Ceritinib for Untreated Anaplastic Lymphoma Kinase-Positive Advanced Non-Small-Cell Lung: An Evidence Review Group Evaluation of a NICE Single Technology Appraisal
}

\author{
Lindsay Claxton ${ }^{1}(0) \cdot$ Joanne O'Connor ${ }^{1} \cdot$ Nerys Woolacott $^{1} \cdot$ Kath Wright $^{1} \cdot$ Robert Hodgson $^{1}$
}

Published online: 22 November 2018

๑) Springer Nature Switzerland AG 2018

Correction to: PharmacoEconomics

https://doi.org/10.1007/s40273-018-0720-8

The title of the article should read:

Ceritinib for Untreated Anaplastic Lymphoma Kinase-Positive Advanced Non-Small-Cell Lung Cancer: An Evidence Review Group Evaluation of a NICE Single Technology Appraisal.

The original article was corrected.

The original article can be found online at https://doi.org/10.1007/ s40273-018-0720-8.

Lindsay Claxton

lindsay.claxton@york.ac.uk

1 Centre for Reviews and Dissemination, University of York, York YO10 5DD, UK 